\title{
Gestão por indicadores em shopping center
}

\author{
Leonardo Fabris Lugoboni \\ Flavio Hourneaux Junior \\ Doutorando em Administração. Universidade de São Paulo (USP) Brasil. leo_fabris@hotmail.com \\ Doutor em Administração. Universidade de São Paulo (USP) Brasil. flaviohj@@uol.com.br \\ Marcus Vinicius Moreira Zittei \\ Doutor em Ciências Contábeis e Administração. Fundação Escola de Comércio Alvares Penteado (FECAP) Brasil. \\ marcuszittei@zittei.com.br \\ Veronice Francisca da Costa Bacharela em Administração. Centro Universitário Adventista de São Paulo (UNASP) Brasil. \\ verinhaferrer@yahoo.com.br \\ Luis Paulo Cristino Mota Bacharel em Administração. Centro Universitário Adventista de São Paulo (UNASP) Brasil. \\ luis_paulo_motta@yahoo.com.br
}

\section{Resumo}

O presente estudo tem como objetivo principal descrever como é feita a gestão por indicadores de desempenho em um shopping center e apresentar os indicadores estratégicos utilizados. O trabalho, de caráter qualitativo e descritivo, analisa o caso de um empreendimento na cidade de Santo André, Estado de São Paulo, e utilizou-se de entrevistas com os gestores responsáveis dos departamentos financeiro, operações, qualidade, marketing, estacionamento, comercial, recursos humanos, segurança e da própria holding, além de análise documental de relatórios aos quais os pesquisadores tiveram acesso. Os resultados apontam que a gestão por indicadores é um elemento importante e crítico para a gestão estratégica e sistêmica do empreendimento, com reflexos na sua competitividade.

Palavras-chave: avaliação de desempenho; indicadores de desempenho; shopping center.

\section{Management by performance indicators in a mall}

\begin{abstract}
The following study has as main goal to describe how the malls' management by performance indicators is done. This essay of qualitative and descriptive character analyses a case of an enterprise located in Santo André city, São Paulo state, and used interviews with managers from the departments of finances, operations, quality, parking lot, commercial, human resource, security and the holding itself, as well as a documentary analysis of reports the researchers were given access. In each one of those sections, the performance indicators used and their relation with the strategy in terms of objectives and goals was identified. The results showed that management by performance indicators is an important and essential element for the strategic and systemic management of enterprises, reflecting in their competitiveness.
\end{abstract}

Keywords: Performance evaluation; Performance indicators; Shopping center. 


\section{INTRODUÇÃO}

A economia brasileira tem demonstrado fortes índices de crescimento dentro do segmento de shopping centers. De acordo com a Associação Brasileira de Shopping Centers (Abrasce, 2013) de 2008 para 2012, o faturamento do setor praticamente dobrou, subindo de 64,6 para 119,5 bilhões de reais por ano. Ainda de acordo com a Abrasce (2013), no ano de 2012, o setor gerou cerca de 877.000 vagas de empregos no Brasil.

Apesar, ou devido a esse desenvolvimento, aumenta a necessidade de uma melhor gestão desses empreendimentos, sendo que o planejamento e a avaliação do desempenho organizacional tornam-se fatores críticos para o sucesso de qualquer organização (Kennerley \& Neely, 2002a). Nesse sentido, os indicadores de desempenho são elementos básicos para a gestão (Denton, 2005; Otley, 2007; Mikušová \& Janecková, 2010), pois fornecem a base para que uma organização avalie se está progredindo em direção aos seus objetivos e ajuda a identificar pontos de melhoraria para o desempenho organizacional (Yasin \& Gomes, 2010).

O presente estudo tem como objetivo principal descrever como é feita a gestão por indicadores de desempenho em um shopping center e apresentar os indicadores estratégicos utilizados. A relevância da pesquisa está na descrição sobre como um importante shopping do Brasil gerencia seu desempenho, toma decisões e utiliza seus indicadores para melhorar seus resultados.

Apesar de diversos setores terem sido estudados sob a ótica da avaliação de desempenho como setor químico (Corrêa \& Hourneaux, 2008), arranjos produtivos locais (Galdámez, Carpinetti \& Gerolamo, 2009) empresas de software (Yokomizo, 2009), gestão pública (Kloot \& Martin, 2000), pequenas empresas (Cocca \& Alberti, 2010), hospitais filantrópicos (Cunha \& Corrêa, 2013), instituições de ensino (Galvão, Corrêa, Alves, 2011; Crispim \& Lugoboni, 2012), não foi possível identificar nenhuma pesquisa descrevendo como um shopping acompanha seu desempenho.

O trabalho, de caráter qualitativo e descritivo, analisa o caso de um shopping center na cidade de Santo André, Estado de São Paulo, e utilizou-se de entrevistas com os gestores responsáveis dos departamentos financeiro, operações, qualidade, marketing, estacionamento, comercial, recursos humanos, segurança e da própria holding, além de análise documental de relatórios aos quais os pesquisadores tiveram acesso. Para cada uma dessas áreas foram identificados os indicadores utilizados e sua relação com a estratégia, em termos de objetivos e metas. Os resultados apontam que a gestão por indicadores é um elemento importante e um crítico para a gestão estratégica e sistêmica dos empreendimentos.

\section{REFERENCIAL TEÓRICO}

\subsection{Importância da avaliação do desempenho da empresa}

A quantificação é um recurso que somente é pertinente quando é associada a um conceito qualitativamente claro e bem estabelecido. Pode-se, e faz sentido, ter um conceito qualitativo que não se pode quantificar. $\mathrm{O}$ inverso, porém, não é válido: uma quantificação somente passa a fazer sentido quando fica claro e bem definido a que conceito (qualitativo) ela se refere (Trzesniak, 2014).

O desempenho de um negócio é ponto-chave para as pesquisas referentes às diversas estratégias administrativas, ocasionando uma contínua busca dos pesquisadores quanto ao estabelecimento das implicações do desempenho para a condução estratégica das organizações, através de uma grande variedade de métodos que visam à operacionalização deste desempenho (Venkatraman \& Ramanujan, 1986).

Conforme Callado, Callado e Almeida, (2008a), a medição de desempenho é uma operação estratégica que pode gerar informações de gestão, pode obter relatórios e indicadores que demonstram como ela está em relação às metas estabelecidas.

A avaliação ou comparação de desempenho é de extrema importância para as empresas, saber analisar a situação atual da empresa, e antever o futuro, é uma vantagem razoável perante os seus concorrentes, na diminuição de incerteza e risco. A empresa que realiza uma avaliação de desempenho consegue realizar mudanças rapidamente, reagindo prontamente ao mercado (Uenoyama, 2007).

A avaliação de desempenho é uma maneira pela qual a organização verifica e mensura se os objetivos traçados em seu planejamento estratégico estão sendo alcançados, para monitorar o andamento das atividades da organização de forma mensurável, conforme Cunha e Corrêa (2013), comparando esses resultados com objetivos estabelecidos e sendo capaz de identificar as causas que resultam o desempenho. Isso as permitiriam comparar o seu 
desempenho com concorrentes ou organizações de outros ramos (benchmarking), demonstrar aos investidores qual o retorno de seus investimentos e verificar se as estratégias organizacionais estão sendo cumpridas.

Com o uso da avaliação de desempenho é possível distribuir melhor os recursos, delegar autoridade de forma mais adequada e visualizar falhas e pontos de melhoria no seu processo. A implementação da avaliação de desempenho consegue vincular a responsabilidade dos gestores aos processos de gestão (Uenoyama, 2007), assim como os sistemas estruturados são importantes para facilitar o gestor na identificação de causa do resultado obtido (Cunha \& Corrêa, 2013).

Com as medidas de desempenho e eficiência sendo utilizadas desde o século XIX, praticamente adotou-se a mensuração relacionada à questão financeira (Tezza, Bornia \& Vey, 2010). Foi recentemente, principalmente a partir da década de 1990, que se reforçou a necessidade de incorporar, além das medidas financeiras tradicionais, indicadores de outras naturezas, levando a ideia de multidimensionalidade do desempenho (Neely, 1999; Kennerley \& Neely, 2002b; Bourne, Neely, Mills \& Platts, 2003).

\subsection{Importância e construção dos indicadores de desempenho}

A mensuração e a avaliação de desempenho têm como elemento fundamental o uso de indicadores. Um indicador de desempenho representa a possibilidade de relacionar os números aos fenômenos observados, através de um conjunto de regras estabelecidas que, por sua vez, seriam os próprios indicadores (De Haas \& Kleingeld, 1999).

O conjunto de indicadores deve ter algumas características que possibilitem a eficácia dos processos de mensuração e avaliação do desempenho na organização: devem ser relevantes; devem ser precisos; devem cobrir um espectro amplo; e devem ser fáceis para avaliação (Roos \& Roos, 1997). Para Rummler e Brache (1994), existem três requisitos básicos para que o estabelecimento de medidas de desempenho propicie um gerenciamento efetivo da organização: eles devem ser sólidos para garantir o monitoramento dos fatores apropriados; o sistema de indicadores deve ter uma característica de totalidade, e não ser simplesmente uma coleção de medidas que não sejam necessariamente relacionadas; e o processo de gerenciamento de desempenho deve converter as medidas aferidas em ação que gere resultados.

Há discordâncias com relação à quantidade de indicadores de desempenho. Kaplan e Norton afirmam que o número de indicadores não chega a ser uma questão problemática, desde que os indicadores sejam interrelacionados e focados em atingir a mesma estratégia essencial (Kaplan \& Norton, 1997), enquanto que o excesso de informação pode dificultar o processo de tomada de decisão. Dessa forma, possuir um conjunto de um pequeno número de indicadores com o objetivo de se reduzir a complexidade de um sistema é a essência da mensuração de desempenho (Perrin, 1998).

A questão da discussão sobre quantidade também se soma a questão de quais os indicadores que devem ser utilizados. Tradicionalmente, os indicadores presentes nos sistemas de mensuração de desempenho apresentam uma natureza financeira (Kaplan \& Norton, 1997). Entretanto, Debusk, Brown e Killough (2003) afirmam que há uma tendência em se utilizar indicadores de desempenho não financeiros devido a três motivos principais: a percepção das limitações dos indicadores financeiros tradicionais; a crescente pressão de competitividade; e a implementação de programas como a administração da qualidade total, que pressupõe o uso de indicadores não financeiros.

Além disso, outros indicadores podem e devem complementar as limitações dos indicadores financeiros, que podem ser enumeradas como: têm uma perspectiva muito histórica e voltada ao passado; apresentam falta de capacidade preditiva; recompensam comportamentos incorretos e voltados ao curto prazo; não permitem uma ação; apreendem as mudanças chaves no negócio somente tardiamente; são agregados e sumarizados demais para guiar uma ação administrativa; são muito departamentalizados ao invés de interfuncionais; e não consideram efetivamente os aspectos intangíveis (Ittner \& Larcker, 1998). Um espectro maior de indicadores deve levar à multidimensionalidade, que, por sua vez, levaria a um melhor desempenho no mercado, em função das crescentes dificuldades de obtenção de largas margens de lucro; a uma percepção das sutilezas das organizações, com informações mais amplas por parte dos analistas e investidores; e, finalmente, à ascendência do papel do consumidor e das inovações feitas pelas organizações (Morgan \& Strong, 2003).

Para Uenoyama (2007), os indicadores de desempenho são indispensáveis para acompanhar a consecução dos objetivos e metas do planejamento estratégico da empresa. O indicador pode atuar de maneira recíproca, permitindo o reajuste dos objetivos e revisão do planejamento estratégico da empresa. Se seu uso for de maneira inadequada, pode confundir mais do que ajudar, uma simplificação exagerada da realidade ou preocupação demasiada em indicadores em vez dos processos da empresa. Em outras palavras, "a definição dos indicadores de 
desempenho a serem utilizados faz parte de uma sequência lógica de procedimentos para desenvolvimento e implementação de um sistema de mensuração e avaliação de desempenho" (Callado, Callado \& Almeida, 2008b, p.19).

Assim, a falta de um sistema de indicadores que "seja eficiente e que esteja em constante melhoramento pode tornar todos os sistemas organizacionais estáticos e estéreis, ao invés do ideal de produtividade e dinamismo que a organização que busca resultados deve priorizar" (Giegold, 1980, p. 5). Dessa forma, uma boa gestão dos indicadores promoveria a priorização da rentabilidade vinda das melhorias contínuas nos processos, melhorando a qualidade e a flexibilidade da organização (Johnson, 1990).

Para Trzesniak (2014), o emprego dos indicadores é especialmente útil e eficaz por três motivos: o gerencial, o de avaliação e o de comunicação. A Demanda Gerencial: uma empresa, um projeto, uma aeronave são sistemas em processo para os quais se almeja um desfecho positivo. Isso exige conhecimento, para conduzir o Universo no sentido desejado, e informações, para as tomadas de decisões adequadas. Um indicador atende adequadamente a demanda gerencial quando o gestor sabe exatamente o que é preciso fazer para ajustar o seu valor, sem a necessidade de retornar ao sistema, em busca de informações adicionais, ou de recorrer a outros indicadores, mais simples e diretos. A Demanda de Avaliação: nesse domínio, os indicadores são planejados e utilizados para colher informações sobre o andamento do processo e a qualidade do seu desfecho. Os objetivos são, entre outros, verificar atendimento a normas, certificação, concessão de financiamento, atribuição de conceitos e prêmios. Indicadores de avaliação não precisam ser concebidos com a preocupação direta de aperfeiçoar o processo, e talvez alguns deles não possam mesmo oferecer essa possibilidade. Mas induzir a melhorias no que está sendo avaliado - ser construtivo, jamais punitivo - constitui-se em uma qualidade importante e, até, imprescindível de boas avaliações. Já na Demanda da Comunicação, finalmente, existem indicadores destinados prioritariamente a comunicar bem. Têm que fazer sentido e impressionar (positiva ou negativamente) as pessoas a que se destinam. Em termos de comunicação especializada pode-se pensar em um gerente com um grande projeto em andamento que precisa convencer a diretoria da empresa a ampliar sua verba, em uma reunião em que poderá apresentar cerca de meia dúzia de informações.

\subsection{O shopping center}

O shopping center é um agrupamento planejado dos varejistas desenvolvido, possuído e administrado como uma unidade que surgiu nos Estados Unidos, na periferia das grandes cidades, como uma alternativa para o varejista atingir um grande número de consumidores conforme Kotler e Armstrong, (2008).

Estes empreendimentos estão substituindo o comércio de rua, com vantagens competitivas empresariais e com benefícios aos clientes. Essa substituição representa a mudança de comportamento da população atual, que busca cada vez mais concentrar os serviços em um só local, por falta de tempo, comodidade e questões de segurança, dentre outros motivos (Underhill, 2004).

Segundo BNDES (2007), a ideia de um centro de compras onde pudessem ser encontrados artigos variados, este local surgiu em Paris no fim do século XVIII, com as chamadas galeries. Nos Estados Unidos (EUA), após a Segunda Guerra Mundial, com o aumento do poder aquisitivo da população, o desenvolvimento da indústria automobilística e a migração da população para as áreas periféricas, teve início o shopping center em sua versão moderna.

Kotler e Armstrong (2008) classificam os shoppings centers em regional, comunitário e de bairros, segundo critérios de qualidade e especialidade das lojas que os compõem e serviços que oferecem, conforme apresentado no Quadro 1. Esta distinção que faz aos tipos de shoppings refere-se mais ao seu tamanho, isto é, ao número de lojas que possuem, do que ao porte da localidade onde estão instalados. Esta segmentação atende aos padrões americanos, em que a indústria de shopping está bastante evoluída, respondendo por um terço das vendas de varejo, mas que ao que tudo indica, alcançou seu ponto de saturação, tendo o número de 34.683 shoppings. 


\begin{tabular}{|c|c|}
\hline Tipo & Características \\
\hline Regional & $\begin{array}{l}\text { Minicentro de uma cidade, com mais de } 50 \text { lojas atraindo consumidores de uma grande } \\
\text { área, têm diversas lojas de departamento e uma variedade de lojas de especialidades: } \\
\text { dentistas, academia de ginástica e bibliotecas. }\end{array}$ \\
\hline Comunitário & $\begin{array}{l}\text { Engloba de } 15 \text { a } 50 \text { lojas de varejo com filial de lojas de departamentos, loja de variedades, } \\
\text { supermercado, lojas de especialidades, escritórios e banco. }\end{array}$ \\
\hline Bairro & $\begin{array}{l}\text { Com } 5 \text { a } 15 \text { lojas, localizam-se em pontos próximos aos consumidores com um } \\
\text { supermercado e várias lojas de serviços, como lavanderias, salão de beleza, farmácia, } \\
\text { locadora, cabeleireiro, loja de ferragens, representando } 87 \% \text { de todas as vendas em varejo } \\
\text { em shopping. }\end{array}$ \\
\hline
\end{tabular}

\section{Quadro 1. Tipos de shopping centers}

Fonte: Kotler e Armstrong (2008, pp. 301-302).

Esses shoppings são classificados também pelo total de área bruta locável, corresponde ao total de área disponível para a locação. Este índice é importante uma vez que o faturamento do shopping está diretamente relacionado aos aluguéis que, por sua vez, estão relacionados ao espaço disponível e ao volume de pessoas e vendas que este espaço é capaz de gerar. É possível observar a classificação por área bruta locável no Quadro 2.

\begin{tabular}{|c|c|c|}
\hline Tipo & Porte & ABL \\
\hline \multirow{4}{*}{ Tradicional } & Mega & acima de $60.000 \mathrm{~m}^{2}$ \\
\hline & Regional & de 30.000 a $59.999 \mathrm{~m}^{2}$ \\
\hline & Médios & de 20.000 a $29.999 \mathrm{~m}^{2}$ \\
\hline & Pequenos & até $19.999 \mathrm{~m}^{2}$ \\
\hline \multirow{3}{*}{ Especializado } & Grandes & acima de $20.000 \mathrm{~m}^{2}$ \\
\hline & Médios & de 10.000 a $19.999 \mathrm{~m}^{2}$ \\
\hline & Pequenos & até $9.999 \mathrm{~m}^{2}$ \\
\hline
\end{tabular}

\section{Quadro 2. Classificação por tipo de empreendimento}

Fonte: Abrasce (2013)

Com relação especificamente aos aspectos financeiros, a capacidade de auferir receitas é determinante para o sucesso financeiro de um shopping center, conforme Lemos e Rosa (2003). Suas principais fontes de receita são apresentadas no Quadro 3:

\begin{tabular}{cl}
\hline Fonte de receita & \multicolumn{1}{c}{ Descrição } \\
\hline & $\begin{array}{l}\text { A renda de aluguel - mais importante fonte de receita dos empreendedores - é composta } \\
\text { de um percentual sobre o faturamento bruto da loja, chamado aluguel variável, sendo } \\
\text { também fixado um piso mínimo, chamado aluguel fixo, reajustado anualmente. Toda vez } \\
\text { que o aluguel variável não alcança o piso (aluguel fixo), o lojista arca com a diferença } \\
\text { entre os dois. O valor fixo ou variável do aluguel depende da capacidade, previamente } \\
\text { reconhecida, que o lojista possui em atrair público para o shopping. O aluguel variável } \\
\text { parte de cerca de 2,5\% do faturamento bruto, no caso de lojas-âncora, e chega até cerca } \\
\text { de 8\% do faturamento bruto nas lojas-satélite, responsáveis pela maior parcela dos } \\
\text { aluguéis pagos aos empreendedores. }\end{array}$ \\
\hline Fundo de & $\begin{array}{l}\text { É gerido pelo empreendedor, para financiar gastos que resultem em atração de fluxo de } \\
\text { pessoas ao shopping. }\end{array}$ \\
\hline Estacionamento & $\begin{array}{l}\text { Uma das principais receitas do empreendedor. O fato de haver cobrança ou não e o valor } \\
\text { da tarifa podem ser identificados como termômetros do sucesso do shopping, ressalvados } \\
\text { certos casos, incluindo aqueles em que a cobrança é proibida por lei municipal. }\end{array}$ \\
\hline
\end{tabular}

Quadro 3. Principais fontes de receita de um shopping center

Fonte: Lemos e Rosa (2003)

Na sequência será apresentado o panorama do setor no Brasil.

\subsection{Os shoppings centers no Brasil}

Segundo Rocha e Christensen (1999), no Brasil esses complexos surgiram na década de 60, com a inauguração Shopping Center Iguatemi em 1966. Ele tinha algumas diferenças em relação ao modelo americano: a área de estacionamento era menor e a de tráfego interno de clientes era maior. 
Segundo Lemos e Rosa (2003), a atividade de shopping center no Brasil vem crescendo de forma acelerada nas últimas décadas, importante no cenário do comércio varejista dos centros urbanos e, em consequência dessa expansão, avançou sobre o comércio de rua tradicional. Os shopping centers incorporaram grandes lojas de departamentos, supermercados, pequenos comerciantes, prestadores de serviços públicos e privados, tais como postos do Instituto Nacional de Seguridade Social (INSS), agências bancárias, agências de viagens, consultórios médicos, laboratórios e, mais recentemente, centros universitários. A necessidade de atrair as pessoas para dentro dos shoppings também propiciou a incorporação, bem-sucedida, de atividades de entretenimento, com destaque para os cinemas, que estão presentes na maior parte dos shoppings de médio e grande porte.

A Tabela 1 apresenta a distribuição dos shoppings pelas regiões do Brasil. É possível observar que a maior concentração está na região sudeste, onde estão concentrados mais da metade de todos os shoppings do Brasil.

\begin{tabular}{cccc}
\hline Regiões & $\mathbf{N}^{\circ}$ de shoppings & \%de total & ABL \\
\hline Norte & 18 & $3,90 \%$ & 461.071 \\
Nordeste & 61 & $13,30 \%$ & 1.726 .462 \\
Centro-oeste & 42 & $9,20 \%$ & 891.473 \\
Sudeste & 355 & $55,70 \%$ & 6.685 .505 \\
Sul & 82 & $17,90 \%$ & 1.660 .150 \\
\hline Total & 558 & $100 \%$ & 11.424 .661 \\
\hline
\end{tabular}

Tabela 1. Participação por região

Fonte: Abrasce (2013)

A indústria de shopping centers se tornou uma grande propulsora de desenvolvimento, promovendo o crescimento urbano, valorização imobiliária, aprimoramento do comércio local e, consequentemente, gerando empregos. No Brasil são 458 centros de compras em operação até 2013 (Abrasce, 2013). A Tabela 2 apresenta os principais números do setor de shopping centers no país.

\begin{tabular}{lc}
\hline Número total de shoppings & 558 \\
A inaugurar em 2013 (1) & 45 \\
Número previsto para dez. 2013 & 503 \\
Área bruta locável (em milhões $\mathrm{de} \mathrm{m}^{2}$ ) & 11,42 \\
Área construída (em milhões de m²) & 28,92 \\
Vagas para carros & 694.043 \\
Lojas totais & 83631 \\
Lojas-âncora & 2509 \\
Megalojas & 1673 \\
Lojas-satélite & 71.923 \\
Lazer & 836 \\
Lojas de serviços & 6.690 \\
Salas de cinema & 2587 \\
Empregos gerados em 2012 & 877.000 \\
Faturamento estimado em 2012 (em R\$ bilhões) & 119,5 \\
Tráfego de pessoas (milhões por mês) & 398 \\
Vendas em relação ao varejo nacional & $19,00 \%$ \\
\hline
\end{tabular}

Tabela 2. Shopping centers: grandes números Brasil

Fonte: Abrasce (2013)

Assim, percebe-se a complexidade e a multidimensionalidade de aspectos que devem ser observados para a gestão de um shopping center, que serão os aspectos fundamentais para a realização desse estudo. Em seguida, são apresentados os aspectos metodológicos balizadores da pesquisa.

\section{METODOLOGIA DA PESQUISA}

A definição da metodologia pode ser determinada pelo objetivo que a pesquisa deseja alcançar. Assim sendo, são várias as formas de classificar as pesquisas, quanto a sua metodologia. De acordo com Silva e Menezes (2005), pode-se dividir a pesquisa em quatro classificações: quanto à natureza, quanto à abordagem do problema, quantos aos objetivos e aos procedimentos técnicos para desenvolvê-la. 
Essa pesquisa tem o propósito exploratório, de acordo com as classificações de Gil (2010), está desenvolvida por meio de estudos teóricos, envolvendo a revisão bibliográfica nacional e internacional, assim como o estudo em shopping, incluindo seus indicadores, delimitada na região de Santo André.

Os procedimentos técnicos de pesquisa, para Silva e Menezes (2005), ou estratégias de pesquisa para Yin (2005), são classificadas em: pesquisa bibliográfica e estudo de caso que é realizado por meio de análises documentais e entrevistas. O estudo de caso, pelo menos, da forma como é concebido no âmbito da metodologia de pesquisa, constitui uma das muitas modalidades de delineamento. Trata-se, pois, de um dos diversos modelos propostos para a produção de conhecimento em um campo específico, assim também para o experimento ou levantamento de campo (GIL, 2010). Esta pesquisa classifica-se como estudo de caso, pois busca explorar situações da vida real cujos limites não estão claramente definidos, preservando o caráter unitário do objeto estudado e descrever a situação do contexto em que está sendo feita conforme apresentado por Gil (2010).

Para a coleta de dados foi elaborado um roteiro de entrevista semiestruturada com 17 perguntas, que visam capturar a opinião do respondente sobre os indicadores de desempenho, sua utilização e importância para os gestores. $O$ roteiro está apresentado no apêndice desse trabalho.

As entrevistas foram realizadas com os gestores responsáveis: GERAF (gerente do financeiro), GEOP (gerente de operações) / coordenadora de qualidade, GEMARK (gerente de marketing), GEREST (gerente de estacionamento), GECOM (gerente comercial), Gerente de RH (recursos humanos), GESEG (gerente de segurança) e diretora da holding. Buscou-se, dessa forma, contemplar as diversas áreas do negócio, levando a uma visão ampla e sistêmica para entender os aspectos críticos do desempenho do shopping center.

Também foram consultados os seguintes relatórios: Glossário de indicadores do shopping; Apresentações gerenciais e Relatórios de resultados para a matriz. Ao fazer as entrevistas com os gerentes dos departamentos, de marketing, gerente de segurança, gerente de estacionamento, gerente de recursos humanos, gerente de operações, coordenadora de qualidade, gerente comercial, gerente financeiro e a diretora da holding, pesquisou-se quais são os indicadores utilizados pelo shopping, e buscou-se classificá-los por área de atuação.

Para análise dos resultados, as entrevistas foram transcritas, e as informações apresentadas foram categorizadas, corroboradas e enriquecidas pelos documentos analisados.

\section{APRESENTAÇÃO E ANÁLISE DOS RESULTADOS}

\subsection{O Shopping Center XYZ: perfil e resultados gerais da pesquisa}

O Shopping Center XYZ foi inaugurado em 1996, no coração da cidade de Santo André, e recebe, atualmente, um público anual de 12 milhões de pessoas, predominantemente das classes A e B. Com $126.595 \mathrm{~m}^{2}$ de área total e 49.247,15 $\mathrm{m}^{2}$ de área locável, o espaço conta com um completo mix de 276 lojas e 16 lojas-âncora.

No segmento de serviços, o shopping dispõe de um posto da Polícia Federal, para a emissão de passaportes, Detran, Correios, casa lotérica, academia, laboratório, serviço de vallet, seguranças e atendentes.

O shopping conta com quase 2.000 vagas no estacionamento, uma praça de alimentação com 1.200 lugares e 20 lojas onde acontecem mais de 10 eventos durante o ano. O shopping também oferece presentes e sorteios de carros, viagens, vale-presentes, brindes, ingressos para shows e espetáculos.

Nessa análise, verificou-se que a administradora da holding tem mais de 280 indicadores operacionais, divididos em departamentos, sendo que os indicadores mais estratégicos para o shopping são: aluguel variável, taxa de ocupação, vendas por $\mathrm{m}^{2}$, inadimplência e receita.

O shopping trabalha com 43 indicadores estratégicos, e eles se dividem por sete departamentos, onde qualidade é responsabilidade do gerente de operações, como se pode ver no quadro de indicadores.

A diretora geral da holding afirma que é utilizado um indicador próprio desenvolvido pelos diretores, juntamente com a equipe estratégica da holding. Outro ponto abordado pelos gerentes de marketing e pelo gerente de operações é o objetivo da utilização de indicadores de desempenho: avaliar o desempenho mensal e anual de toda a organização, checar se as ações propostas estão atingindo o resultado esperado e se o planejamento atual está gerando resultado.

Em relação ao processo decisório, os entrevistados afirmam que as informações geradas por meio de indicadores de desempenho são usadas no planejamento das ações. Ou seja, a pesquisa constatou que os indicadores funcionam como recursos de gestão, uma vez que os resultados alcançados orientam decisões e ações a serem empreendidas no estabelecimento. 
A pesquisa também constatou que o responsável direto pela avaliação de desempenho geral do Shopping XYZ é o superintendente, embora cada gestor conheça o âmbito de sua responsabilidade em relação aos resultados dos indicadores. Por outro lado, a pesquisa apontou que são os gerentes de cada área, os responsáveis pela avaliação de desempenho nos departamentos. O processo de avaliação dos resultados conta com a participação do superintendente do shopping e inicia com a apresentação dos resultados atingidos para cada pessoa responsável dos departamentos. Em seguida, são analisadas as causas dos resultados indesejáveis, permitindo assim, além de analisar falhas, também promover um direcionamento de todos os envolvidos para um mesmo foco.

Conforme relatado por todos os entrevistados, quem cria os indicadores são os diretores da holding do shopping, juntamente com a equipe de estratégias da companhia. São responsáveis também pela alteração ou substituição dos indicadores, em reunião uma vez por ano, avaliam quais os indicadores, e se estes indicadores estão gerando os resultados esperados. Conforme relato da diretora da holding do shopping: "só se altera uma vez por ano".

Analisando a questão "quais são os principais indicadores do shopping", foi verificado que todos os gestores departamentais juntamente com a diretora da holding do shopping consideram como os principais indicadores: 0 financeiro, o NOI (net operating income), que significa o resultado do shopping, a análise de fluxo, análise de vendas, análise de resultados, comparado ao do ano anterior, análise de resultados de qualidade operacional e comercial.

Quando questionado se era considerada causa e efeito entre os indicadores muitos não souberam responder, já o gerente de operações responde citando um exemplo:

[...] vai existir em concorrência futura outros dois shoppings que estão sendo inaugurados então vai ter uma consequência aqui pra gente, uma causa externa que vai gerar uma consequência interna pra gente e que vai fazer cair a receita de estacionamento, cair a receita de loja vai fazer cair a receita em geral, porque o fluxo vai diminuir, porque nós vamos dividir o mercado com mais dois novos players [...].

Quanto aos benefícios da avaliação de desempenho, os gerentes de estacionamento, recursos humanos e gerente de operações responderam que tem uma bonificação para meta atingida, para o departamento.

Segundo relato dos gerentes de marketing, segurança, estacionamento, recursos humanos e financeiro, há fatores positivos ligados à avaliação de desempenho organizacional, como por exemplo, o acompanhamento mais próximo das metas e das ações realizadas para o cumprimento das metas. Os treinamentos, em virtude do não cumprimento das metas, planos de ação gerados, cumprimento maior de prazos de entregas dos relatórios, também são consequências do processo de avaliar o desempenho.

$\mathrm{Na}$ opinião do gerente de marketing, o que dificulta na avaliação de desempenho organizacional são números que não conversam ou que não fazem sentido, e o sistema desatualizado.

Já para os gerentes de operações e recursos humanos, o mercado externo é sempre o maior ofensor; para o gerente de segurança, além do mercado externo, é também o prazo; para a gerente do financeiro é quando a meta não está bem clara.

Para os gerentes departamentais é a meta não estar bem clara na hora da apuração, é a dependência de terceiros, ou mercado externo. Conforme resposta de todos os gerentes dos departamentos e a diretora da holding é a periodicidade com que revisam a estrutura dos indicadores que é feita anualmente.

\subsection{Os indicadores no Shopping Center XYZ}

Após analisar os documentos e relatórios recebidos e o conteúdo das entrevistas, foi possível listar os indicadores mais importantes de cada uma das áreas. Estes são os principais indicadores utilizados para mensurar o desempenho do departamento.

A seguir, são apresentados os indicadores identificados nos diversos departamentos analisados: financeiro, operações, qualidade, marketing, estacionamento, comercial, recursos humanos, segurança e da própria holding.

\subsubsection{Indicadores da área de marketing.}

O Quadro 4 apresenta os indicadores da área de marketing, que, de modo geral, buscam mensurar a relação do shopping com os clientes, principalmente em termos de satisfação na busca da fidelização. 


\begin{tabular}{|l|l|}
\hline \multicolumn{1}{|c|}{ Indicadores } & \multicolumn{1}{c|}{ Descrição } \\
\hline \% SSS Same store sales & Aumentar o lucro total do shopping/vendas para mesmas lojas. \\
\hline No de ocorrências & $\begin{array}{l}\text { Quem previne é a empresa contratada de qualidade (furtos, assaltos, } \\
\text { acidentes). }\end{array}$ \\
\hline $\begin{array}{l}\text { Otimizar gestão FPPI } \\
\text { cumprimento do planejamento }\end{array}$ & $\begin{array}{l}\text { Fundo de Promoção e Propaganda = entidade sem fins lucrativos, que } \\
\text { tem como objetivo planejar e executar a publicidade, eventos, sorteios, e } \\
\text { promoções do shopping e gerir os recursos arrecadados, que constituem } \\
\text { o "caixa", formado a partir de taxas de contribuições mensais obrigatórias } \\
\text { dos lojistas, destinadas a financiar o marketing. }\end{array}$ \\
\hline $\begin{array}{l}\text { NPS (Nota de Pesquisa de } \\
\text { do lojista }\end{array}$ & $\begin{array}{l}\text { Eventos e promoções geradores de lucro, melhorar mix de lazer e } \\
\text { restaurantes, reforma das lojas layout antigo, campanha na hora do } \\
\text { almoço, divulgação do mix de lojas, facebook, site e outros. }\end{array}$ \\
\hline PES (Programa de Excelência em & $\begin{array}{l}\text { Programa de Excelência em Shopping = guia para alcance da excelência } \\
\text { em diversos processos e procedimentos do dia a dia do shopping, com } \\
\text { menor no ocorrências no (shopping) investir em atendimento. }\end{array}$ \\
\hline Cliente oculto marketing & \begin{tabular}{l} 
Nota do cliente. \\
\hline
\end{tabular}
\end{tabular}

Quadro 4. Indicadores da área de marketing

Fonte: Dados da Pesquisa

Aqui, os indicadores ajudam a verificar como o gerente do departamento faz para medir seu desempenho, sendo feito um demonstrativo mês a mês comparado ao ano anterior, dando uma ideia do aumento ou queda do fluxo, e verificando-se o valor gasto em média por cada visitante no shopping, base para determinar os valores de promoções, definir o público frequentador e até o mix ideal de lojas. A área também tem um plano de ação e utiliza ciclo PDCA (Plan, Do, Check, Act) para a gestão dos indicadores.

\subsubsection{Indicadores da área de segurança.}

O Quadro 5 apresenta os indicadores da área de segurança, que, de modo geral, buscam mitigar os riscos na operação do shopping.

\begin{tabular}{|l|l|}
\hline \multicolumn{1}{|c|}{ Indicadores } & \multicolumn{1}{c|}{ Descrição } \\
\hline Custos & Controlar tudo o que deve ser pago (serviço de segurança + bombeiro) \\
\hline Otimizar gestão condominial & $\begin{array}{l}\text { Custo segurança (orgânico + terceiro) + brigada (orgânico + terceiro) } \\
\text { (shopping) }\end{array}$ \\
\hline Gerir risco & $\begin{array}{l}\text { Projeto de prevenção de perdas (\%) (shopping). } \\
\text { Menos perda, mais pontuação. }\end{array}$ \\
\hline $\begin{array}{l}\text { Obter a melhor colocação no } \\
\text { PES }\end{array}$ & $\begin{array}{l}\text { PES (Programa de Excelência em Shopping) maratona de segurança (meios) } \\
\text { (shopping) Documentação/ laudos, menor número de ocorrências. }\end{array}$ \\
\hline $\begin{array}{l}\text { PPP (Projeto Prevenção } \\
\text { Perdas) }\end{array}$ & $\begin{array}{l}\text { Entra com plano de ação para evitar perdas. Por exemplo: estouro na praça } \\
\text { causado pela válvula da máquina de refrigerante ou problema no teto do } \\
\text { loft, com possibilidade de queda de material. }\end{array}$ \\
\hline
\end{tabular}

Quadro 5. Indicadores da área de segurança

Fonte: Dados da Pesquisa

\subsubsection{Indicadores de estacionamento.}

O Quadro 6 apresenta os indicadores da área do estacionamento, que, de modo geral, buscam mensurar a eficiência e o desempenho do estacionamento, como já citado, uma das importantes fontes de receita de um shopping.

\begin{tabular}{|l|l|}
\hline \multicolumn{1}{|c|}{ Indicadores } & \multicolumn{1}{c|}{ Descrição } \\
\hline NOI de estacionamento & $\begin{array}{l}\text { Net Operating Income (resultado operacional líquido). É a receita operacional } \\
\text { líquida = receita operacional bruta (-) custo operacional do empreendedor. }\end{array}$ \\
\hline $\begin{array}{l}\text { Indicador de qualidade } \\
\text { (estacionamento) (shopping) }\end{array}$ & $\begin{array}{l}\text { Melhorar a qualidade e a conformidade operacional, sinalização, placas } \\
\text { indicativas de vagas para idosos, deficientes, altura máxima permitida, enfim } \\
\text { dentro dos padrões exigidos pela lei. }\end{array}$ \\
\hline $\begin{array}{l}\text { Remessa de estacionamento } \\
\text { enviada vs. devida (shopping) }\end{array}$ & $\begin{array}{l}\text { Remessas de documentos e notas promissórias para o CSC (Centro de Serviço } \\
\text { Compartilhado), no prazo. }\end{array}$ \\
\hline
\end{tabular}




\begin{tabular}{|l|l|}
\hline $\begin{array}{l}\text { PES maratona estacionamento } \\
\text { (meios) (shopping) }\end{array}$ & $\begin{array}{l}\text { Programa de excelência em shopping = guia para alcance da excelência em } \\
\text { diversos processos e procedimentos do dia a dia do shopping, manter a } \\
\text { melhor pontuação. }\end{array}$ \\
\hline Tráfego de veículos (shopping) & $\begin{array}{l}\text { Ticket médio é o valor referente à arrecadação média por fluxo. É usado } \\
\text { quando estamos tratando do consumo no shopping. Exemplo, se } 100.000,00 \\
\text { mil pessoas foram ao shopping e a receita de todas as lojas foi de } \\
\mathrm{R} \$ 10.000 .000,00, \text { logo o ticket médio deste shopping é de } \mathrm{R} \$ 100,00 .\end{array}$ \\
\hline
\end{tabular}

Quadro 6. Indicadores de estacionamento

Fonte: Dados da Pesquisa

O objetivo destes indicadores de estacionamento é verificar como o gerente do departamento faz para medir seu desempenho, é o meio pelo qual conseguem medir, pelo número de ticket, o número médio de frequentadores do shopping, pelo ticket, e o valor faturado de todas as lojas. A área utiliza um plano de ação e ciclo PDCA para a gestão dos indicadores.

\subsubsection{Indicadores de Recursos Humanos.}

O Quadro 7 apresenta os indicadores da área de Recursos Humanos, que, de modo geral, buscam mensurar os processos mais importantes do departamento: custo de pessoal, rotatividade, horas extras, tempo de reposição, entre outros.

\begin{tabular}{|l|l|}
\hline \multicolumn{1}{|c|}{ Indicadores } & \multicolumn{1}{c|}{ Descrição } \\
\hline Redução de custo com pessoal & Garantir que o valor gasto não ultrapasse o orçamento. \\
\hline $\begin{array}{l}\text { Dias de vagas em aberto (exceto } \\
\text { vagas de superintendente e } \\
\text { gerente) }\end{array}$ & $\begin{array}{l}\text { Total de dias de vagas em aberto dividido pelo número de vagas (média, } \\
\text { por exemplo, 85 dias). }\end{array}$ \\
\hline SLA reverso CSC & $\begin{array}{l}\text { SLA (Service Level Agreement) = acordo de nível de serviço, a parte de } \\
\text { contrato de serviços entre duas ou mais entidades no qual o nível da } \\
\text { prestação de serviço é definido formalmente. Na prática, o termo é usado } \\
\text { no contexto tempo de entrega de um serviço ou de um desempenho } \\
\text { específico ao CSC, que é o Centro de Serviços Compartilhados. }\end{array}$ \\
\hline $\begin{array}{l}\text { Banco de horas (saldo em horas } \\
\text { positivas) }\end{array}$ & $\begin{array}{l}\text { O número de horas extras da equipe não pode ser maior que 40 horas por } \\
\text { mês. }\end{array}$ \\
\hline TO / Turnover & $\begin{array}{l}\text { É o indicador que mede o percentual de funcionários que saem da } \\
\text { empresa sobre o total de funcionários. }\end{array}$ \\
\hline
\end{tabular}

Quadro 7. Indicadores de recursos humanos

Fonte: Dados da Pesquisa

\subsubsection{Indicadores de operações.}

O Quadro 8 apresenta os indicadores da área de operações, que de modo geral, buscam mensurar a execução das atividades principais em termos de qualidade das operações e de execução dos projetos.

\begin{tabular}{|l|l|}
\hline \multicolumn{1}{|c|}{ Indicadores } & \multicolumn{1}{c|}{ Descrição } \\
\hline $\begin{array}{l}\text { Gerir risco /indicador técnico do } \\
\text { shopping }\end{array}$ & $\begin{array}{l}\text { É uma auditoria que é feita pela empresa contratada pela holding, para } \\
\text { fazer auditoria em nível corporativo que avalia a infraestrutura, a condição } \\
\text { das máquinas, bombas, geradores, escadas rolantes, elevador, casa de } \\
\text { máquinas, enfim tudo o que faz o shopping funcionar e o cliente não vê. }\end{array}$ \\
\hline $\begin{array}{l}\text { Indicador de qualidade } \\
\text { (operações) shopping }\end{array}$ & $\begin{array}{l}\text { Melhorar qualidade e conformidade operacional (pintura, paisagismo, } \\
\text { placas, iluminação). }\end{array}$ \\
\hline $\begin{array}{l}\text { Otimizar gestão condominial, } \\
\text { investimento em infraestrutura } \\
\text { sujeito a orçado vs. realizado do } \\
\text { condomínio }\end{array}$ & $\begin{array}{l}\text { Orçado versus realizado do condomínio sujeito ao investimento em } \\
\text { infraestrutura (shopping). O shopping tem um valor mensal para investir em } \\
\text { algo que seja de infraestrutura e melhoria do shopping. }\end{array}$ \\
\hline $\begin{array}{l}\text { PES operações (meios) } \\
\text { (shopping) }\end{array}$ & $\begin{array}{l}\text { Guia para alcance da excelência em diversos processos e procedimentos do } \\
\text { dia a dia do shopping. Garantir excelência no shopping é tudo o que o } \\
\text { shopping precisa ter de documentos legais para o funcionamento. Ex. AVCB, } \\
\text { tudo é ranqueado em nível de Brasil. }\end{array}$ \\
\hline
\end{tabular}




\begin{tabular}{|c|c|}
\hline $\begin{array}{l}\text { Cronograma físico financeiro de } \\
\text { CAPEX (Capital Expenditure), } \\
\text { MANOI (Marginal Annualized Net } \\
\text { Operating Income) e projetos } \\
\text { específicos do shopping }\end{array}$ & $\begin{array}{l}\text { Cronograma físico financeiro de CAPEX = é o montante de recurso a ser } \\
\text { desembolsado para o desenvolvimento, expansão ou melhoria de algum } \\
\text { recurso da companhia; MANOI = resultado operacional líquido anualizado } \\
\text { marginal, é o aumento esperado no resultado operacional líquido da } \\
\text { empresa a partir de uma aquisição ou de um projeto de greenfield. É } \\
\text { utilizado frequentemente na mensuração das metas de M\&A (Margens \& } \\
\text { Aquisições) = fusões e aquisições. É a área responsável por analisar } \\
\text { shoppings existentes no mercado e realizar as aquisições dos próprios e } \\
\text { projetos específicos do shopping. }\end{array}$ \\
\hline $\begin{array}{l}\text { Processos d } \\
\text { operações }\end{array}$ & $\begin{array}{l}\text { Fazer vistoria antes de qualquer inauguração e toda vez que uma loja } \\
\text { fechar, para ver se tudo está nas conformidades (extintores, obra conforme } \\
\text { a planta). }\end{array}$ \\
\hline
\end{tabular}

Quadro 8. Indicadores de operações

Fonte: Dados da Pesquisa

O objetivo desses indicadores de operações é verificar como o gerente do departamento faz para medir seu desempenho, apresenta projeto realizado versus orçado pelo empreendedor. É a área responsável por analisar shoppings existentes no mercado e realizar as aquisições destes e projetos específicos do shopping, tem também o aumento esperado no resultado operacional líquido da empresa a partir de uma aquisição.

\subsubsection{Indicadores de qualidade.}

O Quadro 9 apresenta os indicadores da área de qualidade, que, de modo geral, buscam mensurar, principalmente, o impacto financeiro na qualidade das atividades e operações do empreendimento.

\begin{tabular}{|l|l|}
\hline \multicolumn{1}{|c|}{ Indicadores } & \multicolumn{1}{c|}{ Descrição } \\
\hline CAPEX cronograma financeiro & $\begin{array}{l}\text { Cronograma financeiro = todo investimento feito pelo empreendedor para } \\
\text { melhoria, ar-condicionado, reforma do estacionamento, docas e banheiros, } \\
\text { executar os projetos não ultrapassando os gastos. }\end{array}$ \\
\hline $\begin{array}{l}\text { Auditoria/empresa contratado } \\
\text { pela holding }\end{array}$ & $\begin{array}{l}\text { Vistoriar os serviços, como ligações elétricas, tubulação, ligação de água, } \\
\text { esgoto. }\end{array}$ \\
\hline Tempo de análise de projetos & $\begin{array}{l}\text { Analisar os projetos de novas lojas/ reformas no menor tempo possível para } \\
\text { não atrasar a inauguração das lojas. }\end{array}$ \\
\hline Lojas reformadas & $\begin{array}{l}\text { Projetar reforma de lojas antigas ou que tenham novo layout em outros } \\
\text { shoppings e continuam aqui com layout antigo. }\end{array}$ \\
\hline Indicador de qualidade & Pintura, paisagismo, placas, iluminação. \\
\hline PES maratona & $\begin{array}{l}\text { Programa de excelência em shopping = guia para alcance da excelência em } \\
\text { diversos processos e procedimentos do dia a dia do shopping, manter a } \\
\text { melhor pontuação. }\end{array}$ \\
\hline
\end{tabular}

Quadro 9. Indicadores de qualidade

Fonte: Dados da Pesquisa

Percebe-se, aqui, uma certa sobreposição da área de qualidade sobre a área de operações, com ambas tratando de aspectos muito similares ou idênticos.

\subsubsection{Indicadores da área comercial.}

O Quadro 10 apresenta os indicadores da área comercial, que, de modo geral, está diretamente relacionado com o desempenho financeiro das operações da empresa.

\begin{tabular}{|l|l|}
\hline \multicolumn{1}{|c|}{ Indicadores } & \multicolumn{1}{c|}{ Descrição } \\
\hline Leasing spread renovações & Comparação entre o AMM (área mínima de mapeamento) médio do novo \\
(shopping) & contrato e o último AMM faturado do contrato antigo, para próprio \\
& espaço de repasses de lojas de vagas. O indicador é contabilizado pela \\
& data de início de vigência do contrato. Cálculo do LS novas: \\
& $\begin{array}{l}\text { LSN = novo AMM médio-1 } \\
\text { último AMM cobrado no contrato anterior }\end{array}$ \\
\hline
\end{tabular}




\begin{tabular}{|c|c|}
\hline & $\begin{array}{l}\text { Ex.: contrato de } 5 \text { anos com último aluguel de } R \$ 3.000,00 \text {. Novo aluguel } \\
A M M R \$ 5.000,00=(5.000 \times 65)-(5.000 \times 2) / 65=R \$ 4.846,15 \text { leasing spread = } \\
(4.846,15 / 3.000)-1=62 \%\end{array}$ \\
\hline $\begin{array}{l}\text { Renovação de } 90 \% \text { dos contratos } \\
\text { vencidos e a vencer em } 2012\end{array}$ & Renovar contratos antes de vencer. \\
\hline Desconto (\%) (shopping) & $\begin{array}{l}\text { Desconto de aluguel = considera-se desconto todo abatimento de } \\
\text { aluguel concedido ao lojista depois de firmado o contrato ou auferido em } \\
\text { processo de auditoria (desconto em aluguel \%). O desconto deve ser } \\
\text { considerado para aluguel mínimo, percentual, complementar, CDU } \\
\text { (Cessão de Direito de Uso), TT (Taxa de Transferência) e TI (Taxa de } \\
\text { Interveniência) de lojas, quiosques, antenas, depósitos e mídia. A } \\
\text { diferença entre carência e desconto é concedida após a assinatura do } \\
\text { contrato, e a carência é prevista em contrato. Taxa de interveniência é a } \\
\text { taxa paga pelo novo lojista ao comercializador, referente ao serviço de } \\
\text { comercialização, no momento da troca de lojistas. }\end{array}$ \\
\hline $\begin{array}{l}\text { PES maratonas comerciais (meios) } \\
\text { (shopping) }\end{array}$ & $\begin{array}{l}\text { Programa de excelência em shopping = guia para alcance da excelência } \\
\text { em diversos processos e procedimentos do dia a dia do shopping, }\end{array}$ \\
\hline $\begin{array}{l}\text { CDU linearizado + TT+ mídia } \\
\text { (shopping) }\end{array}$ & $\begin{array}{l}\text { CDU (Cessão de Direito de Uso) que é o valor cobrado pelo direito de } \\
\text { utilizar um ponto comercial, quando é firmado um contrato de locação ( } 5 \\
\text { anos ou mais). Ele é pago pelo novo lojista ao antigo lojista (no caso de } \\
\text { repasse) ou ao empreendedor (no caso de loja vaga). Os valores de CDU } \\
\text { devem ser contabilizados com base na competência acordada em } \\
\text { contrato com lojista + TT (Taxa de Transferência) em situação na qual } \\
\text { existe a troca de lojistas no shopping, o lojista que está entrando precisa } \\
\text { pagar, além do CDU para o lojista atual, uma taxa de transferência para o } \\
\text { empreendedor + mídia do shopping. }\end{array}$ \\
\hline
\end{tabular}

Quadro 10. Indicadores da área comercial

Fonte: Dados da Pesquisa

O objetivo desses indicadores da área comercial é verificar como o gerente do departamento faz para medir seu desempenho, por exemplo, as vendas/mês dividida por $\mathrm{m}^{2}$ da loja; fornece uma ideia comparativa entre o aluguel pago pelo lojista, sua receita e sua capacidade de arcar com seus compromissos financeiros no curto prazo, entre outros aspectos.

\subsubsection{Indicadores da área financeira.}

O Quadro 11 apresenta os indicadores da área financeira, que de modo geral, mensuram a receita e lucratividade do shopping.

\begin{tabular}{|l|l|}
\hline \multicolumn{1}{|c|}{ Indicadores } & \multicolumn{1}{c|}{ Descrição } \\
\hline \multirow{4}{*}{ Atingir NOI } & $\begin{array}{l}\text { NOI (resultado operacional líquido) = receita operacional bruta (-) custo } \\
\text { operacional do empreendedor = } \\
\text { lucro = se positivo, mostra que o investimento colocado no Investimento } \\
\text { shopping trouxe resultado positivo em vendas ou em redução de custo }\end{array}$ \\
\cline { 2 - 3 } $\begin{array}{l}\text { Aluguel variável lojas + aluguel variável mall - custo de auditoria } \\
\text { comercial }\end{array}$ & $\begin{array}{l}\text { Leasing spread renovações = comparação entre o AMM aluguel médio mensal } \\
\text { do novo contrato e o último AMM aluguel médio mensal faturado do contrato } \\
\text { antigo, para o próprio espaço repasses de lojas vagas. O indicador é } \\
\text { contabilizado pela data de início de vigência do contrato. Cálculo do LS novas: } \\
\text { LSN= novo AMM médio -1 } \\
\text { último AMM cobrado no contrato anterior } \\
\text { Ex.: contrato de } 5 \text { anos com último aluguel de R\$3.000,00 } \\
\text { Novo aluguel AMM R\$5.000,00= (5.000x65) -(5.000x2) /65=R\$4.846,15 leasing } \\
\text { spread = (4.846,15/3.000) -1=62\% }\end{array}$ \\
\hline $\begin{array}{l}\text { Atingir receita de serviços e } \\
\text { receitas complementares }\end{array}$ & $\begin{array}{l}\text { Taxa de comercialização + taxa de administração = a taxa de comercialização } \\
\text { paga pelos empreendedores, nos shoppings, no qual a administradora possui } \\
\text { sócios, para a administradora comercializar o empreendimento. Normalmente, } \\
\text { essa taxa é separada em duas: uma para loja e outra para mall e mídia + a taxa }\end{array}$ \\
\hline
\end{tabular}




\begin{tabular}{|l|l|}
\hline & $\begin{array}{l}\text { de administração, que é paga pelos empreendedores, nos shoppings, nos quais } \\
\text { a administradora possui sócios para administrar o empreendimento. }\end{array}$ \\
\hline Garantir orçamento & $\begin{array}{l}\text { Garantir cobrado vs. realizado do condomínio (shopping) condicionado a não } \\
\text { pagar 5\% das notas fiscais de serviço atrasadas. }\end{array}$ \\
\hline $\begin{array}{l}\text { Garantir cobrança com } \\
\text { qualidade }\end{array}$ & Inadimplência mês /aluguel (shopping). \\
\hline
\end{tabular}

\section{Quadro 11. Indicadores da área financeira}

Fonte: Dados da Pesquisa

O objetivo dos indicadores da área financeira é verificar como o gerente do departamento faz para medir seu desempenho; se, por exemplo, o lucro dividido pelo investimento for positivo, o investimento aplicado no shopping trouxe resultado positivo em vendas ou em redução de custo. A área também tem um plano de ação e utiliza ciclo PDCA para a gestão dos indicadores.

\section{CONSIDERAÇÕES FINAIS}

Os indicadores de desempenho são compreendidos como um dos principais instrumentos utilizados para mensurar o desempenho (Denton, 2005; Otley, 2007; Mikušová \& Janecková, 2010) de um processo, departamento ou uma organização.

Paralelo a isso, a economia brasileira tem demonstrado fortes índices de crescimento dentro do segmento de shopping center (Abrasce, 2013). Existem investimentos no setor, visto o grande número de melhorias que estão sendo feitas nestes centros de compras na região de Santo André.

Dentro deste contexto, esta pesquisa verificou a utilização das avaliações por indicadores em um shopping e como estes indicadores exercem o papel fundamental no desempenho, na informação e condução do processo gerencial.

Após todas as análises, pode-se concluir que os indicadores são extremamente importantes para a tomada de decisão, conforme relatado pelos entrevistados. Observou-se que embora nenhuma ferramenta específica seja utilizada para mensurar o desempenho (BSC, por exemplo), os indicadores são utilizados em larga escala para controlar os resultados, conforme proposto por De Haas e Kleingeld (1999); Otley (2007); Mikušová e Janechová (2010).

Foi indicado na análise de resultados que todas as áreas do shopping center possuem indicadores para medir rotinas e plano de ação, que demonstram como atingiram seus resultados, e exercem papel fundamental no desempenho na informação e condução do processo gerencial, assumindo assim uma certa multidimensionalidade, conforme proposto por Neely (1999); Kennerley e Neely (2002b); Bourne et al. (2003).

Verificou-se que os indicadores fazem parte do dia a dia de todos os colaboradores, por meio de metas preestabelecidas em todos os níveis, constituindo uma visão multidimensional do shopping. E sendo possível encontrar mais de 280 indicadores operacionais, observou-se que a gestão tem o foco nos 43 indicadores estratégicos, divididos em sete departamentos, reforçando a importância dos indicadores e da gestão estratégica que eles possibilitam.

Como limitações desta pesquisa aponta-se a limitação do método, com os resultados não sendo representativos de outros shoppings. No entanto, como se tratam de negócios muito similares, os resultados poderiam ser avaliados para possível aplicação em outros empreendimentos. Sugere-se que, para trabalhos futuros, possa-se verificar a extensão do uso dos indicadores aqui levantados, por meio de uma pesquisa do tipo survey.

\section{REFERÊNCIAS}

ABRASCE. (2013). Portal do Shopping. Disponível em: http://www.abrasce.com.br. Consultado em 15 de dezembro de 2013.

BNDES. (2007). Setor de Shopping Center no Brasil: Evolução Recente e Perspectivas, Rio de Janeiro, BNDES Setorial. Bourne, M., Neely, A., Mills, J., \& Platts, K. (2003). Implementing performance measurement systems: A literature review, International Journal of Business Performance Management, 5(1), 1-24. 
Callado, A. L. C.; Callado, A. A. C., \& Almeida, M. A. (2008a). A utilização de indicadores de desempenho não financeiros em organizações agroindustriais: Um estudo exploratório. Organizações Rurais e Agroindustriais, 10(1), 35-48.

Callado, A. L. C.; Callado, A. A. C., \& Almeida, M. A. (2008b). Determinando padrões de utilização de indicadores de desempenho: Um estudo em micro e pequenas empresas da cidade de João Pessoa. Contabilidade, Gestão e Governança, 11(1+2), 18-29.

Cocca, P., \& Alberti, M. (2010). A framework to assess performance measurement systems in SMEs. International Journal of Productivity and Performance Management, 59(2), 186-200.

Corrêa, H. L., \& Hourneaux JR, F. (2008). Sistemas de mensuração e avaliação de desempenho organizacional: Estudo de casos no setor químico no Brasil. Revista Contabilidade e Finanças - USP, 19(48), 50-64.

Crispim, S., \& Lugoboni, L. (2012). Avaliação de desempenho organizacional: Análise comparativa dos modelos teóricos e pesquisa de aplicação nas Instituições de Ensino Superior da Região Metropolitana de São Paulo. Revista Portuguesa e Brasileira de Gestão, 11(1), 41-54.

Cunha, C. A. J., \& Corrêa, H. L. (2013). Avaliação De Desempenho Organizacional: Um Estudo Aplicado Em Hospitais Filantrópicos. RAE Revista De Administração De Empresas, 53(5), 485-499).

Debusk, G. K.; Brown, R. M., \& Killough, L. N. (2003). Components and relative weights in utilization of dashboard measurement systems like the Balanced Scorecard. The British Accounting Review, 35(3), 215-231.

De Haas, M., \& Kleingeld, A. (1999). Multilevel design of performance measurement systems: Enhancing strategic dialogue throughout the organization. Management Accounting Research, 10(3), 233-261.

Denton, D. K. (2005). Measuring relevant things. International Journal of Productivity and Performance Management, 54(4), 278-287.

Galdámez, E. V. C., Carpinetti, L. C. R., \& Gerolamo, M. C. (2009). Proposta de um sistema de avaliação do desempenho para arranjos produtivos locais. Gestão e Produção, 16(1), 133-151.

Galvão, H. M., Corrêa, H. L., \& Alves, J. L. (2011). Modelo de avaliação de desempenho global para instituição de ensino superior. Revista de Administração da UFSM, 4(3), 425-441.

Giegold, W. C. (1980). Avaliação de desempenho e o processo APO: Uma abordagem de instrução programada. São Paulo, McGraw Hill do Brasil.

Gil, A. C. (2010). Como elaborar projetos de pesquisa. São Paulo, Atlas.

Ittner, C. D., \& Larcker, D. (1998). Innovations in performance measurement: Trends and research implications. Journal of management accounting research, 10, 205-238.

Johnson, H. T. (1990). Performance measurement for competitive excellence: Measures for manufacturing excellence. In R. S. Kaplan (Coord.), Measures for manufacturing excellence (pp. 63-89). Boston, Harvard Business School Press.

Kaplan, R. S., \& Norton, D. P. (1997). Balanced Scorecard: A estratégia em ação. Rio de Janeiro, Campus.

Kennerley, M., \& Neely, A. (2002a). A framework of the factors affecting the evolution of performance measurement systems. International Journal Of Operations And Production Management, 22(11), 1222-1245.

Kennerley, M., \& Neely, A. (2002b). Performance measurement frameworks: A review. In A. Neely (Ed.), Business performance measurement: Theory and practice (pp. 145-15). Cambridge: Cambridge University Press.

Kloot, L., \& Martin, J. (2000). Strategic performance management: A balanced approach to performance management issues in local government. Management Accounting Research, 11(2), 231-251.

Kotler, P., \& Armstrong, G. (2008). Princípios de marketing. São Paulo, Pearson Educación.

Lemos, M. L. F., \& Rosa, S. E. S. (2003). O segmento de shopping centers no Brasil e o BNDES. Disponível em: www.bndes.gov.br/conhecimento/setorial/get 4is12.pdj.

Mikušová, M., \& Janečková, V. (2010). Developing and implementing successful key performance indicators. Proceedings World Academy of Science, Engineering and Technology, Paris, 66, 1231-1243.

Morgan, R. E., \& Strong, C. A. (2003). Business performance and dimensions of strategic orientation. Journal of Business Research, 56(3), 163-176.

Neely, A. (1999). The performance measurement revolution: Why now and what next? International Journal of Operations and Production Management, 19(2), 205-228.

Otley, D. (2007). Accounting performance measurement: A review of its purposes and practices. International Journal of Business Performance Management, 3(2/3/4), 11-35.

Perrin, B. (1998). Effective use and misuse of performance measurement. American Journal of Evaluation, 19(3), 367379).

Rocha, A., \& Christensen, C. (1990). Marketing: Teoria e prática no Brasil. São Paulo, Atlas.

Roos, G., \& Roos, J. (1997). Measuring your company's intellectual performance. Long Range Planning, 30(3), 413-426.

Rummler, G. A., \& Brache, A. P. (1994). Melhores desempenhos das empresas. São Paulo, Makron Books.

Silva, E. L., \& Menezes, E. M. (2005). Metodologia da pesquisa e elaboração da dissertação. Florianópolis, UFSC.

Tezza, R., Bornia, A. C., \& Vey, I. H. (2010). Sistemas de medição de desempenho: Uma revisão e classificação da literatura. Gestão e Produção, 17(1), 75-93.

Trzesniak, P. (2014). Indicadores quantitativos: Como obter, avaliar, criticar e aperfeiçoar. Navus: Revista de Gestão e Tecnologia. (4(2), pp. 05-18). 
Uenoyama, A. T. (2007). Avaliação de desempenho global aplicado em pequenas empresas do setor de serviços: escritório de contabilidade (Trabalho de conclusão em Administração, Faculdade de Economia, Administração e Contabilidade, Universidade de São Paulo, São Paulo).

Underhill, P. (2004). A magia dos shoppings. São Paulo: Elsevier Brasil.

Venkatraman, N., \& Ramanujam, V. (1986). Measurement of business performance in strategy research: a comparison of approaches. Academy of Management Review, 11(4), 801-814.

Yasin, M. M., \& Gomes, C. F. (2010). Performance management in service operational settings: A selective literature examination. Benchmarking: An International Journal, 17(2), 214-231.

Yin, R. K. (2005). Estudos de caso: Planejamento e métodos. Porto Alegre, Bookman.

Yokomizo, C. A. (2009). Avaliação de desempenho organizacional: Um estudo exploratório em empresas brasileiras de desenvolvimento de software (Dissertação de Mestrado, Faculdade de Economia, Administração e Contabilidade, Universidade de São Paulo, São Paulo). Recuperado de http://www.teses.usp.br/teses/disponiveis/12/12139/tde-16122009-153626/pt-br.php

\section{APÊNDICE - INSTRUMENTO DE COLETA DE DADOS ROTEIRO DE QUESTÕES PARA ENTREVISTA}

01. O shopping utiliza algum método avaliação de desempenho organizacional pré-formatado como, por exemplo, o BSC?

02. Em sua opinião, qual o principal objetivo da utilização de indicadores de desempenho?

03. As decisões são tomadas com base em informações geradas através dos Indicadores de desempenho?

04. Quem são os responsáveis pela avaliação de desempenho geral?

05. Quem são os responsáveis pela avaliação de desempenho nos departamentos?

06. Com que periodicidade é feita a avaliação de desempenho geral do shopping?

07. Com que periodicidade é feita a avaliação de desempenho departamental do shopping?

08. Com que periodicidade vocês revisam a estrutura dos indicadores?

09. Quais são os principais indicadores do shopping?

10. Os indicadores são agrupados por departamentos, processos outros?

11. Quem é responsável pela criação dos indicadores?

12. Quem é responsável pela alteração ou substituição dos indicadores?

13. É considerada relações de causa e efeito entre os indicadores? Como?

14. Quais os principais benefícios decorrentes da avaliação de desempenho?

15. Quais são as desvantagens ou problemas decorrentes da avaliação de desempenho?

16. Quais os fatores que facilitam a avaliação de desempenho?

17. Quais os fatores que dificultam a avaliação de desempenho? 